\title{
Screening for new primary cancers in cancer survivors compared to non-cancer controls: a systematic review and meta-analysis
}

\author{
Mark Corkum • Jill A. Hayden • George Kephart • \\ Robin Urquhart • Coralynne Schlievert • \\ Geoffrey Porter
}

Received: 10 January 2013 / Accepted: 4 March 2013 / Published online: 5 May 2013

(C) The Author(s) 2013. This article is published with open access at Springerlink.com

\begin{abstract}
Purpose The goal of this study was to synthesize evidence comparing cancer screening receipt between cancer survivors and non-cancer controls by conducting a systematic review and meta-analysis.

Methods We searched PubMed, EMBASE, and CINAHL databases from inception through April 1, 2010 using search terms related to cancer, survivorship, and cancer screening. Studies were included if they reported a comparison of cancer screening receipt between cancer survivors and non-cancer controls. We performed a meta-analysis on the effect of cancer survivorship on breast, cervical, colorectal, and prostate cancer screening receipt.

Results Our search strategy identified 1,778 titles, of which 20 met our inclusion/exclusion criteria. In our meta-analyses, cancer survivors were more likely to be screened for breast, cervical, colorectal, and prostate cancer than non-cancer controls (pooled odds ratio, 1.27; $95 \%$ CI, 1.19-1.36). We
\end{abstract}

Research Support: Canadian Institutes of Health Research Knowledge Synthesis Grant, Nova Scotia Health Research Foundation Student Research Award.

M. Corkum · J. A. Hayden $(\bowtie) \cdot$ G. Kephart • C. Schlievert •

G. Porter

Department of Community Health and Epidemiology,

Dalhousie University, 5790 University Ave,

Halifax, NS, Canada

e-mail: Jill.Hayden@cdha.nshealth.ca

R. Urquhart · G. Porter

Cancer Outcomes Research Program, Cancer Care Nova Scotia,

Halifax, NS, Canada

G. Porter

Department of Surgery, Dalhousie University, Halifax, NS, Canada observed significant heterogeneity between studies, most of which remained unexplained after subgroup and sensitivity analyses. Important contextual factors, such as how screening programs operate, were not reported in the primary literature. Many cancer survivors (along with non-cancer controls) still did not receive cancer screening.

Conclusion Compared with non-cancer controls, cancer survivors receive more frequent screening for new primary breast, cervical, colorectal, and prostate cancers. Future research should seek to determine whether increased uptake of cancer screening is associated with improved outcomes during cancer survivorship.

Implications for Cancer Survivors Our systematic review and meta-analysis demonstrated that cancer survivors received more frequent screening for second primary breast, cervical, colorectal, and prostate cancers than non-cancer controls. As many cancer survivors are at an increased risk of developing a second primary cancer, future research should seek to determine whether this increased uptake of cancer screening in cancer survivors leads to improved outcomes during cancer survivorship.

Keywords Early detection of cancer · Neoplasms . Second primary cancer $\cdot$ Survivors $\cdot$ Systematic review

\section{Introduction}

A current and future challenge for healthcare systems is to determine how to best provide long-term follow-up care to the growing prevalence of cancer survivors, estimated to number over 28 million worldwide [1]. An often overlooked, but nonetheless important, component of follow-up care for cancer survivors is screening for new primary cancers [2]. For 
most malignancies, a cancer survivor's risk of developing a second primary cancer is at least as great as the general population. The epidemiology of second primary cancers is complex, and is a function of common risk factors, genetic links, and late carcinogenic effects from treatment of the primary cancer [3]. Among cancer survivors, often the risk of developing a second primary cancer at a different anatomical site can be much greater than the general population [4-9].

Conflicting theories suggest that cancer survivors, as individuals with a comorbid condition, may be either more or less likely to receive preventive care. One theory [10] and several researchers [11-13] have hypothesized that cancer survivors may receive more frequent screening due to increased contact with the healthcare system. Increased contact with the healthcare system and a recommendation from a primary care physician are both strongly associated with the uptake of cancer screening in the general population [14-17]. Conversely, the competing demands model [18] and other researchers [19, 20] have hypothesized that despite an increased amount of contact with the healthcare system, a cancer survivor's previous cancer diagnosis may shift healthcare workers' attention away from other preventive health services such as screening for new primary cancers.

While two prior systematic reviews have compared receipt of general preventive healthcare (including cancer screening) in cancer survivors and the general population $[21,22]$, the volume of available literature has substantially increased since these reviews were published. In addition, these two reviews reached conflicting conclusions, with Wilkins and Woodgate concluding "the prevalence of secondary prevention practices among cancer survivors is generally lower than recommended" [22], but Khan et al. concluding "cancer screening is generally well managed through normal channels and is adequate amongst survivors of adult cancer in the United States" [21]. An additional review by Treanor and Donnelly assessed health services utilization among cancer survivors, concluding "Overall, there is a need to improve access to care for all cancer survivors" [23]. However, this review did not compare health services utilization between cancer survivors and the general population. Given the conflicting results of these prior reviews, the objective of this review was to synthesize evidence comparing cancer screening receipt between cancer survivors and non-cancer controls.

\section{Methods}

To evaluate the above objective, we conducted a systematic review using methods similar to those advocated by the Cochrane Collaboration [24]. We systematically identified and included observational studies that compared the receipt of any cancer screening test between cancer survivor and non-cancer control group populations. Our research question was developed and refined in consultation with healthcare professionals, program managers/administrators, and other decision makers and stakeholders from the cancer care community during interactive workshops.

Data sources and search strategy

We searched three electronic databases (PubMed, EMBASE, and CINAHL; all available years to April 1, 2010) using a combination of MeSH terms and keywords relating to cancer, cancer survivorship, and cancer screening. The PubMed search strategy is available in the Appendix; the EMBASE and CINAHL search strategies used similar terms. No date or language restrictions were used in the search strategy. Reference lists of included studies and previous reviews were screened to identify additional articles. Previous reviews were identified through our search strategy.

Study selection and data abstraction

Studies that measured and compared the receipt of cancer screening in both cancer survivor and a non-cancer control group were included in this review. We included all definitions of a cancer survivor in this study, regardless of time since diagnosis or initial cancer site. We included studies of both adult and childhood cancer survivors. Secondary survivors, e.g., family members of the cancer survivor, were not eligible for inclusion in this review. All cancer screening sites and tests were eligible for inclusion, regardless of whether the screening was opportunistic or programmatic in nature. Studies that measured screening receipt outside of commonly recommended age ranges were included and explored with subgroup analysis. Unpublished literature was sought through contact with content experts.

A standardized study selection and data abstraction form was used. The initial literature screen of titles and abstracts was done by one author (MC) in order to remove citations that were clearly not relevant to the study objectives. Application of the study inclusion criteria to the full-text articles and abstraction of included articles was conducted independently by two reviewers (MC, CS) with formal systematic review training. If necessary, disagreements were resolved through consensus and consultation with a third reviewer $(\mathrm{JH})$. If available, appropriately adjusted odds ratios were favoured over unadjusted estimates. If odds ratio estimates were not reported in the primary study, crude odds ratios were calculated from raw data. Data for individual screening tests [for example, fecal occult blood testing (FOBT) and endoscopy for colorectal cancer screening] were recorded 
separately whenever possible. Study authors were contacted to retrieve missing data.

\section{Risk of bias assessment}

Study level risk of bias was assessed using four categories selected from quality assessment tools used to assess prognosis studies and randomized controlled trials of intervention effectiveness $[25,26]$, and modified to fit the review question and types of observational studies included in this review. These four risk of bias categories used were: (1) Selection bias; (2) Definition of cancer survivorship [low: long-term survivors (all $\geq 5$ years); moderate: majority long-term survivors; high: time since diagnosis not measured or short-term survivors]; (3) Measurement of screening receipt (low: administrative data; moderate: self-report); and (4) Adjustment for confounding or use of a matched cohort. These risk of bias assessments were used to guide sensitivity analyses. Other categories explored in our subgroup and sensitivity analyses include the use of an exclusively elderly population (greater than age 65), the use of a childhood cancer survivor population, and the use of upper and/or lower age limits reflecting screening guidelines.

\section{Analysis}

We performed a meta-analysis on the effect of cancer survivorship on breast, cervical, colorectal, and prostate cancer screening receipt, supplemented with a thoughtful narrative discussion. Odds ratio effect estimates by cancer site and screening rate were pooled using a random effect generic inverse variance model with Review Manager 5.0 (Cochrane Collaboration, Oxford, UK) software. Meta-analyses were not conducted for skin and testicular cancer screening due to

Fig. 1 Flowchart showing selection of articles for inclusion in the systematic review the small number of studies reporting these outcomes $(n=1$ and $n=2$, respectively).

An overall summary estimate of the association between cancer survivorship and cancer screening was calculated using data from all included studies and any screening site. We selected and pooled the single odds ratio estimate from each included study that represented the screening site with the lowest standard error. This decision rule was determined a priori, and selected to minimize possible selection bias. Heterogeneity was measured using the $I^{2}$ statistic [24]. The narrative synthesis included studies which could not be quantitatively combined and analyzed, results from the risk of bias assessment, and other potential sources of heterogeneity from the meta-analysis, such as study-level demographic and cancer survivor information.

When a study separately reported two different screening tests for a single cancer site, our decision rule was to choose the screening test we felt was more likely to be included in a programmatic, population-level screening intervention for that site. For example, in studies that separately reported the receipt of FOBT and endoscopy colorectal cancer screening, we included the FOBT screening test estimate in the colorectal cancer screening overall estimate. When multiple studies presented data from the same cohort, we avoided double counting participants by only including the single study with the largest sample size in the metaanalysis. Sensitivity analyses were conducted to determine whether changing these decision rules modified our results.

\section{Results}

The flow of study selection and reasons for full-text article exclusion are presented in Fig. 1. Table 1 summarizes the characteristics of the 20 studies which met our inclusion

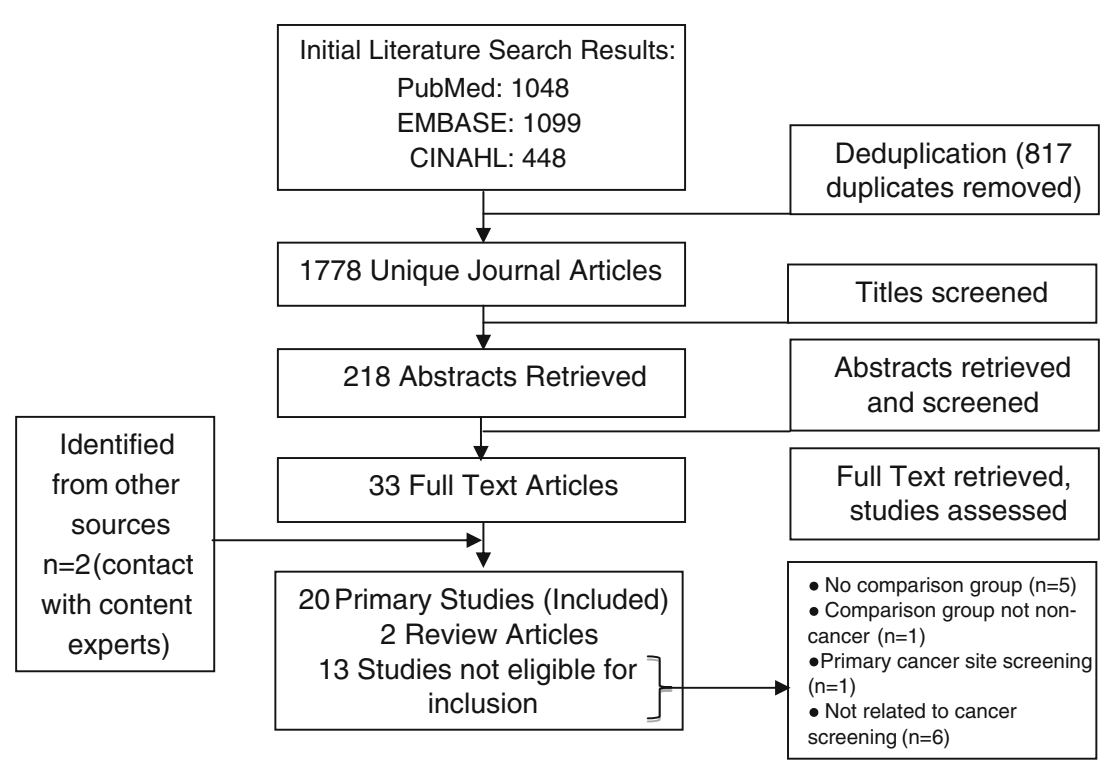


Table 1 Characteristics of included studies

\begin{tabular}{|c|c|c|c|c|c|c|c|c|c|c|c|c|c|}
\hline \multicolumn{13}{|c|}{ Cancer Sites S } & \\
\hline$\underline{\text { Study }}$ & Year & Country & $\frac{\text { Number of Participants }}{\text { (survivors/controls) }}$ & Survivor Characteristics & $\begin{array}{l}\text { Initial Cancer } \\
\text { Diagnosis Type }\end{array}$ & \multicolumn{3}{|c|}{$\begin{array}{c}\text { Study Design/Exposure } \\
\frac{\text { Measurement/Outcome }}{\text { Measurement }}\end{array}$} & 罱 & $\mid$ & 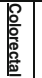 & 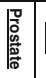 & 㕸 \\
\hline Aparicio-Ting [27] & 2003 & USA & $112 / 2062$ & $\begin{array}{c}34 \% \text { between age } 50-64,100 \% \\
\text { female, } 100 \% \text { Hispanic }\end{array}$ & Mixed & cs & SR & SR & & 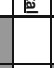 & + & \\
\hline Bellizzi [28] & 2005 & USA & $7,384 / 121,347$ & $\begin{array}{c}52.7 \% \geq \text { age } 65,60.6 \% \text { female, } 88.5 \% \\
\text { white ethnicity }\end{array}$ & Mixed & CS & $\mathrm{SR}$ & SR & & & & & \\
\hline Bishop [11] & 2010 & North America & $662 / 158$ & $\begin{array}{l}\text { Median age: } 49.1,62 \% \text { female, } 92 \% \\
\text { Caucasian ethnicity }\end{array}$ & Mixed & CS & AD & SR & & & & & \\
\hline Breslau [12] & 2010 & USA & $1,502 / 31,911$ & $\begin{array}{c}\begin{array}{c}\text { Mean age: } 66.8,100 \% \text { female, } 76.3 \% \\
\text { white ethnicity }\end{array} \\
\end{array}$ & Breast Cancer & CS & $\mathrm{SR}$ & SR & & & & & \\
\hline Duffy [19] & 2006 & USA & $85 / 340$ & $\begin{array}{c}\text { Mean age: } 61.7,100 \% \text { female, } 85.9 \% \\
\text { Caucasian /other ethnicity } \\
\end{array}$ & Breast Cancer & cs & $\mathrm{SR}$ & SR & & & & & \\
\hline Earle [29] & 2003 & USA & $5,965 / 6,062$ & $\begin{array}{l}\text { Mean age: } 78.7,100 \% \text { female, } 89 \% \\
\text { white ethnicity }\end{array}$ & Breast Cancer & $\mathrm{RC}$ & $\mathrm{AD}$ & $A D$ & & & & & \\
\hline Earle [20] & 2004 & USA & $14,884 / 16,659$ & $\begin{array}{c}\text { Mean age: } 79.9,57.6 \% \text { female, } 86.4 \% \\
\text { white ethnicity }\end{array}$ & Colorectal Cancer & $\mathrm{RC}$ & $A D$ & $A D$ & & & & & \\
\hline Grunfeld [30] & $\mathrm{n} / \mathrm{a}$ & Canada & $21,111 / 105,340$ & $\begin{array}{l}\text { Mean age: } 58.6,86 \% \text { female, no } \\
\text { ethnic information }\end{array}$ & Mixed & $\mathrm{RC}$ & $A D$ & $A D$ & & & & & \\
\hline Hudson [41] & 2009 & USA & $109 / 641$ & $\begin{array}{l}\text { Mean age: } 68.7,59 \% \text { female, } 80 \% \\
\text { white ethnicity }\end{array}$ & Mixed & CS & $\mathrm{SR}$ & $\mathrm{SR}+\mathrm{CR}$ & & & & & \\
\hline Khan [31] & 2010 & United Kingdom & $29,244 / 116,418$ & $\begin{array}{l}\text { Mean age: } 70.7,73.4 \% \text { female, no } \\
\text { ethnic information }\end{array}$ & Mixed & $\mathrm{RC}$ & $A D$ & $A D$ & & & & & \\
\hline Kwon [32] & 2009 & Canada & $3,473 / \mathrm{n} / \mathrm{a}$ & $\begin{array}{c}\text { Mean age: } 63,100 \% \text { female, no ethnic } \\
\text { information }\end{array}$ & Endometrial Cancer & $\mathrm{RC}$ & $\mathrm{AD}$ & $A D$ & & & & & \\
\hline Mayer [33] & 2007 & USA & $619 / 2,141$ & $\begin{array}{c}\text { Mean age: } 58,65.5 \% \text { female, } 81.5 \% \\
\text { white ethnicity }\end{array}$ & Mixed & CS & $\mathrm{SR}$ & $\mathrm{SR}$ & & & & & \\
\hline McBean [35] & 2008 & USA & $14,575 / 14,575$ & $\begin{array}{l}31.9 \% \text { between ages } 67-74,100 \% \\
\text { female, } 94.3 \% \text { white ethnicity }\end{array}$ & Uterine Cancer & $\mathrm{RC}$ & $A D$ & $A D$ & & & & & \\
\hline McBean [34] & 2009 & USA & $7,666 / 36,433$ & $\begin{array}{c}\text { Mean age: } 73.6,100 \% \text { female, } 85 \% \\
\text { white ethnicity }\end{array}$ & Colorectal Cancer & $\mathrm{RC}$ & $\mathrm{AD}$ & $A D$ & & & & & \\
\hline $\mathrm{Ng}[36]$ & 2008 & USA & $511 / 224$ & $\begin{array}{l}\text { Median age: } 44,51 \% \text { female, no } \\
\text { ethnic information available }\end{array}$ & Hodgkin's Lymphoma & CS & $A D$ & $\mathrm{SR}$ & & & & & \\
\hline \multirow{2}{*}{ Oeffingert [37] } & \multirow{2}{*}{2009} & \multirow{2}{*}{ North America } & $551 / 622$ & $\begin{array}{l}\text { Chest RT: } 46.3 \% \text { between ages } 40-50 \text {, } \\
100 \% \text { female, } 92.4 \% \text { white }\end{array}$ & \multirow{2}{*}{ Mixed } & \multirow{2}{*}{ cs } & \multirow{2}{*}{$A D$} & \multirow{2}{*}{ SR } & & & & & \\
\hline & & & $561 / 622$ & $\begin{array}{l}\text { No Chest RT: } 45.8 \% \text { between ages } 40- \\
50,100 \% \text { female, } 93.2 \% \text { white }\end{array}$ & & & & & & & & & \\
\hline Snyder (a) [39] & 2009 & USA & $1961 / 1961$ & $\begin{array}{c}\text { Mean age: } 75,100 \% \text { female, } 90 \% \\
\text { white ethnicity }\end{array}$ & Breast Cancer & $\mathrm{RC}$ & $A D$ & $A D$ & & & & & \\
\hline Snyder (b) [38] & 2009 & USA & $23,731 / 47,127 \neq \dagger$ & $\begin{array}{l}\begin{array}{c}\text { Mean age: } 75.7,100 \% \text { female, } 90 \% \\
\text { white ethnicity }\end{array} \\
\end{array}$ & Breast Cancer & $\mathrm{RC}$ & $A D$ & $A D$ & & & & & \\
\hline Trask [13] & 2005 & USA & $2,151 / 30,195$ & $\begin{array}{c}\text { Mean age: } 61.9,59.7 \% \text { female, } 90 \% \\
\text { white ethnicity }\end{array}$ & Mixed & CS & $\mathrm{SR}$ & SR & & & & & \\
\hline Yeazel [40] & 2004 & North America & $9,434 / 2,667$ & $\begin{array}{l}\text { No age information, } 46.8 \% \text { female, no } \\
\text { ethnic information }\end{array}$ & Mixed & CS & $A D$ & $\mathrm{SR}$ & & & & & \\
\hline
\end{tabular}

$C S$ Cross-Sectional Survey, $R C$ Retrospective Cohort Study, $S R$ Self-Reported exposure/outcome, $A D$ Administratively determined exposure/ outcome, $C R$ Chart Review

${ }^{a}$ Study contained two cancer survivor groups: one survivor cohort received chest radiotherapy, the other did not

${ }^{b}$ Study contained two controls groups: 23,731 controls with mammogram in same year as survivor's dx., 23,396 controls with the same comorbidity score

criteria [11-13, 19, 20, 27-41]. Forty-eight cancer screening sites were reported in these studies: 14 breast, 11 cervical, 11 colorectal, 6 prostate, 1 skin, and 2 testicular. Only one study was conducted outside North America [32], which was conducted in the United Kingdom. Three overlapping study data sources were observed: the National Health Interview Survey [13, 28]; the Ontario Cancer Registry [30, 32]; and the Childhood Cancer Survivor Study [37, 40].

The demographics of the cancer survivors in the included studies varied greatly, and ranged from childhood cancer survivors to elderly populations. The predominant ethnicity, when reported, was white/Caucasian, with only one study focusing on an ethnic minority [27], which was Hispanic. Most studies contained survivor populations with mixed initial cancer diagnosis types $(n=10)$; the most common single initial cancer diagnosis type reported upon was breast cancer $(n=5)$.

Mammography was used for breast cancer screening in all studies except one which measured receipt of either a clinical breast examination or mammogram [11]. Cervical cancer screening consisted of the receipt of a Pap smear in all studies.
Colorectal cancer screening consisted of the receipt of FOBT, endoscopy procedures (colonoscopy, sigmoidoscopy, or proctoscopy), barium enema, or some combination of these three. Prostate cancer screening consisted of the receipt of a prostate specific antigen (PSA) test in all studies, except one that measured receipt of either a PSA or digital rectal examination.

The screening timeframes varied greatly between studies, and ranged from within the last 12 months to ever/never being screened. The most common screening timeframes were: breast cancer screening (2-year interval, 7/14 studies), cervical cancer screening (3-year interval, 7/14 studies), colorectal cancer screening (FOBT, 1-year interval, 4/9 studies; endoscopy, 5- or 10-year intervals, 4/11 studies), and prostate cancer screening (1-year interval, 4/6 studies). The proportion of cancer survivors and controls screened varied greatly between studies, and appeared to be influenced by the age of the participants in each study, the length of screening timeframe (longer screening timeframes resulted in a greater proportion of both cancer survivors and controls receiving screening), 
and screening site (lower screening rates for colorectal cancer than breast or cervical cancer). Across all screening sites, a large proportion of both cancer survivors and non-cancer controls did not receive adequate screening for new primary cancers, as defined by the screening recommendations used in each primary study.

Cancer survivors were more likely to receive screening for new primary cancers than non-cancer controls across all four cancer sites where a meta-analysis was conducted, as well as for skin and testicular cancer screening. Across all studies, cancer survivors were $27 \%$ more likely to receive screening for new primary cancers compared to non-cancer controls [odds ratio (OR), 1.27; $95 \%$ confidence interval (CI), 1.19-1.36]. Meta-analyses for breast, cervical, colorectal, and prostate cancer screening can be seen in Fig. 2. Cancer survivors were $19 \%$ more likely to receive breast cancer screening (OR, 1.19; $95 \%$ CI, 1.06-1.34), $22 \%$ more likely to receive cervical cancer screening (OR, 1.22; $95 \%$ CI, 1.12-1.33), $19 \%$ more likely to receive colorectal cancer screening (OR, 1.19; $95 \%$ CI, 1.10-1.30), and $22 \%$ more likely to receive prostate cancer screening (OR, 1.22; $95 \%$ CI, 1.10-1.36).

Two studies could not be incorporated into our metaanalyses. Duffy et al. [19] used different definitions of
Fig. 2 Meta analyses for breast, cervical, colorectal, and prostate cancer screening. Generic inverse variance random effects model

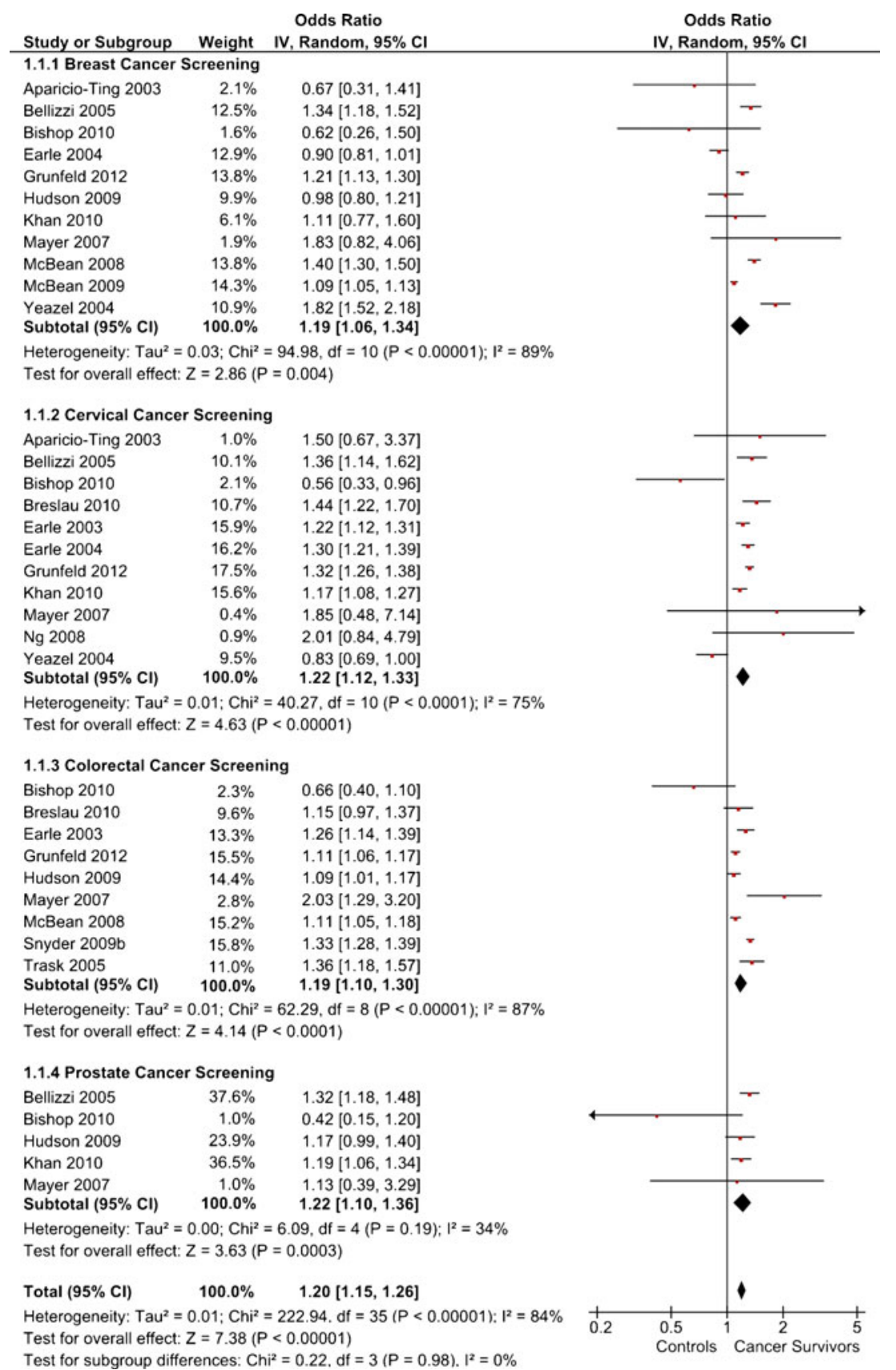


Table 2 Sensitivity and subgroup analyses for breast, cervical, and colorectal cancer screening

\begin{tabular}{|c|c|c|c|}
\hline & $\begin{array}{l}\text { Breast cancer screening } \\
\text { Summary odds ratio esti }\end{array}$ & $\begin{array}{l}\text { Cervical cancer cancer screening } \\
5 \% \mathrm{CI})\end{array}$ & Colorectal cancer screening \\
\hline \multirow[t]{2}{*}{ All studies } & $1.19(1.06-1.34)$ & $1.22(1.12-1.33)$ & $1.19(1.10-1.30)$ \\
\hline & $n=11$ & $n=11$ & $n=9$ \\
\hline \multicolumn{4}{|l|}{ Study characteristics } \\
\hline \multirow[t]{2}{*}{ Elderly population $(65+)$} & $1.12(0.91-1.37)$ & $1.26(1.18-1.34)$ & $1.23(1.08-1.40)$ \\
\hline & $n=3$ & $n=2$ & $n=3$ \\
\hline \multirow[t]{2}{*}{ Non-elderly population } & $1.24(1.05-1.46)$ & $1.19(1.04-1.36)$ & $1.16(1.05-1.29)$ \\
\hline & $n=8$ & $n=9$ & $n=6$ \\
\hline \multirow[t]{2}{*}{ Childhood cancer survivors } & $1.17(0.41-3.28)$ & $0.87(0.53-1.43)$ & $0.66(0.40-1.10)$ \\
\hline & $n=2$ & $n=3$ & $n=1$ \\
\hline \multirow[t]{2}{*}{ Non-childhood cancer survivors } & $1.15(1.02-1.28)$ & $1.28(1.22-1.34)$ & $1.21(1.11-1.31)$ \\
\hline & $n=9$ & $n=8$ & $n=8$ \\
\hline \multicolumn{4}{|c|}{ Ages of cancer survivors/controls within screening guidelines } \\
\hline \multirow[t]{2}{*}{ Adequate lower and upper age limits } & $1.06(0.95-1.19)$ & $1.14(0.95-1.37)$ & $1.11(1.06-1.17)$ \\
\hline & $n=5$ & $n=4$ & $n=1$ \\
\hline \multirow[t]{2}{*}{ No lower and upper age limits } & $1.34(1.13-1.59)$ & $1.28(1.16-1.41)$ & $1.21(1.10-1.33)$ \\
\hline & $n=6$ & $n=7$ & $n=8$ \\
\hline \multicolumn{4}{|l|}{ Risk of bias categories } \\
\hline \multicolumn{4}{|l|}{ (1) Selection bias } \\
\hline \multirow[t]{2}{*}{ Low/moderate risk } & $1.16(1.02-1.30)$ & $1.27(1.21-1.33)$ & $1.22(1.11-1.34)$ \\
\hline & $n=7$ & $n=6$ & $n=5$ \\
\hline \multirow[t]{2}{*}{ High risk } & $1.25(0.78-2.02)$ & $1.08(0.70-1.65)$ & $1.14(0.92-1.42)$ \\
\hline & $n=4$ & $n=5$ & $n=4$ \\
\hline \multicolumn{4}{|l|}{ (2) Adequate cancer survivor selection } \\
\hline \multirow[t]{2}{*}{ Low/moderate risk } & $1.23(1.09-1.40)$ & $1.22(1.12-1.33)$ & $1.18(1.09-1.29)$ \\
\hline & $n=9$ & $n=10$ & $n=7$ \\
\hline \multirow[t]{2}{*}{ High risk } & $0.96(0.78-1.17)$ & $1.50(0.67-3.37)$ & $1.21(0.99-1.47)$ \\
\hline & $n=2$ & $n=1$ & $n=2$ \\
\hline \multicolumn{4}{|l|}{ (3) Screening measurement } \\
\hline \multirow[t]{2}{*}{ Administrative data } & $1.14(0.99-1.30)$ & $1.26(1.19-1.33)$ & $1.20(1.08-1.33)$ \\
\hline & $n=5$ & $n=4$ & $n=4$ \\
\hline \multirow[t]{2}{*}{ Self-reported } & $1.22(0.93-1.61)$ & $1.16(0.87-1.54)$ & $1.19(1.00-1.43)$ \\
\hline & $n=6$ & $n=7$ & $n=5$ \\
\hline \multicolumn{4}{|c|}{ (4) Controlling for confounding/using a matched cohort } \\
\hline \multirow[t]{2}{*}{ Low/moderate risk } & $1.22(1.02-1.38)$ & $1.24(1.15-1.34)$ & $1.21(1.11-1.31)$ \\
\hline & $n=9$ & $n=9$ & $n=8$ \\
\hline \multirow[t]{2}{*}{ Unadjusted studies (high risk) } & $0.65(0.37-1.15)$ & $0.87(0.33-2.29)$ & $0.66(0.40-1.10)$ \\
\hline & $n=2$ & $n=2$ & $n=1$ \\
\hline
\end{tabular}

appropriate cervical cancer screening in their cancer survivor (annual screening) and non-cancer control (biennial screening) groups, and reported that cancer survivors were as likely to receive an annual Pap smear as non-cancer survivors were to receive a biennial Pap smear (OR, 0.98; 95 \% CI, 0.60-1.60). Kwon et al. [32] compared receipt of breast and cervical cancer screening among cancer survivors to a general population screening rate, and found that cancer survivors were about twice as likely to receive breast cancer screening (cancer survivors, $64 \%$; general population, $31 \%$ ) and colorectal cancer screening (cancer survivors, $30 \%$; general population, $15 \%$ ) during their study follow-up period. We did not include Kwon et al. [32] into our meta-analyses for two reasons: first, the study population overlapped with the study by Grunfeld et al. [30], which was larger; second, this was the only included study that used general population screening rates as a comparison group.

There was significant heterogeneity observed between studies for breast $(n=11)$, cervical $(n=11)$, and colorectal $(n=9)$ screening sites $\left(I^{2}=89 \%, 75 \%\right.$, and $87 \%$ respectively). No single study accounted for the statistically significant heterogeneity for these sites. There was no significant heterogeneity observed between the five studies for prostate cancer screening 
( $\left.I^{2}=34 \%, p=0.19\right)$, and therefore, we did not conduct subgroup or sensitivity analyses for prostate cancer screening.

Risk of bias varied considerably between studies, ranging from studies using linked administrative databases with low risk of selection and measurement bias, to higher risk of bias studies using responses from self-reported surveys. Most studies using self-reported surveys had low response rates, introducing a further potential source of bias. There was considerable variation between studies' lengths of cancer survivorship follow-up, with some studies exclusively focusing on long-term survivors, while others contained a wide range of cancer survivorship follow-up time. Risk of bias assessments for each individual study are available by contacting the authors.

To explore potential sources of heterogeneity in the breast, cervical, and colorectal cancer screening meta-analyses, we conducted several sensitivity and subgroup analyses, presented in Table 2. Two categories were found to be statistically significantly different in colorectal cancer screening: studies that did not control for confounding or use a matched cohort, and studies that used a cohort of childhood cancer survivors. These differences were localized to a single study, and are unlikely to be a clinically significant source of heterogeneity. No other statistically significant subgroup or sensitivity analyses were found. There was no significant effect on our overall metaanalysis results when we conducted a sensitivity analysis by changing our decision rule to exclude studies with overlapping study populations.

\section{Discussion}

Our meta-analyses indicate that cancer survivors were more likely to receive screening for new primary cancers across all screening sites included in this review (19\% more likely to receive breast and colorectal cancer screening, $22 \%$ more likely to receive cervical and prostate cancer screening). Taking the effect estimate with the lowest standard error from all studies included in our meta-analysis, cancer survivors overall were $27 \%$ more likely to receive screening for new primary cancers.

While cancer survivors were more likely to receive screening for new primary cancers at each of the screening sites reported in this review, this finding must be interpreted in light of the receipt of cancer screening as a whole. Studies in our review reported that many individuals from both the general population and cancer survivor subpopulation did not receive screening tests recommended for the detection of new primary cancers.

Our study has several strengths. We used a rigorous search strategy which identified a yet-to-be published primary study. We were able to use two authors to abstract data in an effort to minimize data abstraction errors. Our metaanalysis and sensitivity/subgroup analyses were planned a priori. Finally, we tailored our review question and reporting of results to meet the needs of healthcare professionals, program managers/administrators, and other decision makers by holding interactive workshops with key stakeholders throughout the review process.

Our study limitations largely mirror the limitations of the included literature. As only 20 studies were identified, subgroup and sensitivity analyses were likely underpowered to detect potential differences. Important contextual factors were not available for analysis in our systematic review, such as how screening programs local to each study operate (e.g., whether screening programs actively target specific age groups, or depend on primary care- or self-referral), and the degree to which follow-up care is integrated with cancer screening programs. These contextual factors could be a potential source of hidden heterogeneity in our study. Many studies contained incomplete information, which we were mostly able to overcome through contact with study authors. Few studies reported results separately for short- or long-term cancer survivors. Some studies did not use upper or lower age limits to compare receipt of cancer screening between cancer survivors and non-cancer controls. There were inconsistencies between studies' use of screening timeframes, which often did not reflect national recommendations for population-based cancer screening. As the studies included in our systematic review are predominantly from the USA, it is unclear whether the summary estimates in this study are applicable to other healthcare systems.

We conducted a subgroup analysis to examine whether cancer survivors might have higher uptake of cancer screening outside typical age restricted screening recommendations compared to non-cancer controls. This could have presented a source of bias in studies which did not use an upper age restriction. Healthcare providers or cancer survivors may recognize that cancer survivors are at a greater risk, and recommend starting or ending screening at earlier/later ages compared to the general population. However, our subgroup analysis found that studies without upper or lower age restrictions were not a significant source of heterogeneity. This finding is mirrored in studies that only contained an exclusively elderly population ( $\geq$ age 65 ), where we observed no significant difference in screening receipt. Future research should compare the receipt of screening within and outside guideline-based age recommendations to further explore whether the differences in screening uptake exclusively occur outside screening guideline age recommendations.

The two studies that were not included in our meta-analyses appeared to reach similar conclusions as the included literature. Despite using an annual screening timeframe for cancer survivors, and a biennial screening timeframe for non-cancer controls, Duffy et al. [19] found that cancer survivors were as likely to receive annual screening as non-cancer controls were to receive biennial screening. This suggests that if similar 
screening timeframes were used for these two populations, cancer survivors would be screened more frequently than non-cancer controls. Kwon et al. [32] reported absolute screening differences that were much greater than any other study included in our review. This finding may be influenced by the researchers not restricting their analysis to guideline-based age recommendations, the inclusion of many survivors outside of screening age recommendations, and their comparison group being age-standardized general population screening rates.

In the absence of evidence which directly examines screening efficacy among cancer survivors, several studies have demonstrated that many cancer survivor populations are at an increased risk of developing second primary cancers [4-9]. Long-term cancer survivors, or short-term cancer survivors who are likely to survive long term based on the clinical characteristics of their disease, should be encouraged to meet population-based screening recommendations. Future research should directly measure the efficacy and cost-effectiveness of cancer screening among cancer survivors, and also seek to determine whether the optimal screening frequency for cancer survivors differs from the general population.

No studies in this review reported attempts to implement interventions to increase cancer screening receipt among cancer survivors. As cancer survivors represent a high-risk population, such interventions could have an impact on reducing the likelihood of cancer survivors being diagnosed with late-stage second primary cancers. Interventions that have been shown to increase screening uptake in the general population include: reminders, small media (e.g., videos and printed materials), one-on-one education, and reducing structural barriers (e.g., reducing travel distances and increasing hours of operation) [42]. Providing healthcare providers with assessment and feedback has also been shown to increase screening rates [42]. It is possible that these same interventions would increase the uptake of cancer screening among cancer survivors as well.

In conclusion, this study demonstrates that cancer survivors, a population that may be at a greater risk of developing a new primary cancer, are more likely to receive screening for new primary cancers than non-cancer controls. These results should be interpreted in light of suboptimal cancer screening rates in both cancer survivors and the general population. Whether increasing uptake of cancer screening is associated with improved outcomes during the cancer survivorship period should be a focus of future research.

Acknowledgments Funding for this research project was provided by the Canadian Institutes of Health Research through a Knowledge Synthesis Grant. The authors would like to thank those who participated in the workshops for contributing to the clinical context of this work.

Open Access This article is distributed under the terms of the Creative Commons Attribution License which permits any use, distribution, and reproduction in any medium, provided the original author(s) and the source are credited.

\section{Appendix}

Table 3 PubMed Search Strategy

\begin{tabular}{lll}
\hline$\# 1$ & "Neoplasms by Histologic Type"[Mesh] & 1153087 \\
$\# 2$ & "Neoplasms by Site"[Mesh] & 1420041 \\
$\# 3$ & "Neoplasms, Second Primary"[Mesh] & 8006 \\
$\# 4$ & "Neoplasms, Multiple Primary"[Mesh] & 24727 \\
$\# 5$ & malign* [tiab] & 322530 \\
$\# 6$ & tumour [tiab] & 125997 \\
$\# 7$ & tumor [tiab] & 573419 \\
$\# 8$ & cancer [tiab] & 728755 \\
$\# 9$ & $\# 1$ OR \#2 OR \#3 OR \#4 OR \#5 OR \#6 OR \#7 OR \#8 & 2263065 \\
$\# 10$ & "Preventive Health Services"[Mesh] & 339610 \\
$\# 11$ & "Early Detection of Cancer"[Mesh] & 759 \\
$\# 12$ & "Mass Screening"[Mesh] & 79128 \\
$\# 13$ & screen* [tiab] & 327138 \\
$\# 14$ & $\# 10$ OR \#11 OR \#12 OR \#13 & 611106 \\
$\# 15$ & "Survivors"[Mesh] & 9554 \\
$\# 16$ & "previous malignancy" & 103 \\
$\# 17$ & "previous cancer" & 180 \\
$\# 18$ & "previous diagnosis" & 1083 \\
$\# 19$ & survivor* [tiab] & 46731 \\
$\# 20$ & \#15 OR \#16 OR \#17 OR \#18 OR \#19 & 51822 \\
$\# 21$ & \#9 AND \#14 AND \#20 & 1048 \\
\hline & & \\
\hline
\end{tabular}

\section{References}

1. Lance Armstrong Foundation LIVESTRONG ${ }^{\circledR}$ Highlights Global Cancer Burden and the 28 Million Cancer Survivors Around the World. . Available from: http://www.marketwire.com/press-release/ livestrongr-highlights-global-cancer-burden-28-million-cancersurvivors-around-world-1295062.htm. Accessed 20 May 2011.

2. Hewitt ME, Greenfield S, Stovall E. From cancer patient to cancer survivor: lost in transition. Washington, DC: National Academies Press; 2006.

3. Travis LB. The epidemiology of second primary cancers. Cancer Epidemiol Biomark Prev. 2006;15:2020-6.

4. Henderson TO, Amsterdam A, Bhatia S, Hudson MM, Meadows AT, Neglia JP, et al. Systematic review: surveillance for breast cancer in women treated with chest radiation for childhood, adolescent, or young adult cancer. Ann Intern Med. 2010;152:444-55.

5. Lee KD, Lu CH, Chen PT, Chan CH, Lin JT, Huang CE, et al. The incidence and risk of developing a second primary esophageal cancer in patients with oral and pharyngeal carcinoma: a population-based study in Taiwan over a 25 year period. BMC Cancer. 2009;9:373-83.

6. Travis LB, Curtis RE, Storm H, Hall P, Holowaty E, Van Leeuwen $\mathrm{FE}$, et al. Risk of second malignant neoplasms among long-term survivors of testicular cancer. J Natl Cancer Inst. 1997;89:1429-39.

7. Youlden DR, Baade PD. The relative risk of second primary cancers in Queensland, Australia: a retrospective cohort study. BMC Cancer. 2011;11:83-94.

8. Hemminki K, Li X, Dong C. Second primary cancers after sporadic and familial colorectal cancer. Cancer Epidemiol Biomark Prev. 2001;10:793-8. 
9. Evans HS, Moller H, Robinson D, Lewis CM, Bell CM, Hodgson $\mathrm{SV}$. The risk of subsequent primary cancers after colorectal cancer in southeast England. Gut. 2002;50:647-52.

10. Feinstein A. The pre-therapeutic classification of co-morbidity in chronic disease. J Chronic Dis. 1970;23:455-68.

11. Bishop MM, Lee SJ, Beaumont JL, Andrykowski MA, Rizzo JD, Sobocinski KA, et al. The preventive health behaviors of long-term survivors cancer and hematopoietic stem cell transplantation compared to matched controls. Biol Blood Marrow Transplant. 2009;16:207-14.

12. Breslau ES, Jeffery DD, Davis WW, Moser RP, McNeel TS, Hawley S. Cancer screening practices among racially and ethnically diverse breast cancer survivors: results from the 2001 and 2003 California health interview survey. J Cancer Surviv. 2010;4:1-14.

13. Trask PC, Rabin C, Rogers ML, Whiteley J, Nash J, Frierson G, et al. Cancer screening practices among cancer survivors. Am J Prev Med. 2005;28:351-6.

14. Mandelblatt J, Kanetsky PA. Effectiveness of interventions to enhance physician screening for breast cancer. J Fam Pract. 1995;40:162-71.

15. Fox SA, Siu AL, Stein JA. The importance of physician communication on breast cancer screening of older women. Arch Intern Med. 1994;154:2058-68.

16. Arnadottir G, Jonsson FH, Sigurethardottir V, Bovbjerg D, Valdimarsdottir HB. Predictors of mammography adherence among Icelandic women. Laeknabladid. 2000;86:108-14.

17. Mandelblatt JS, Yabroff KR. Effectiveness of interventions designed to increase mammography use: a meta-analysis of provider-targeted strategies. Cancer Epidemiol Biomark Prev. 1999;8:759-67.

18. Jaen CR, Stange KC, Nutting PA. Competing demands of primary care: a model for the delivery of clinical preventive services. J Fam Pract. 1994;38:166-74.

19. Duffy CM, Clark MA, Allsworth JE. Health maintenance and screening in breast cancer survivors in the United States. Cancer Detect Prev. 2006;30:52-7.

20. Earle CC, Neville BA. Under use of necessary care among cancer survivors. Cancer. 2004;101:1712-9.

21. Khan NF, Ward A, Watson E, Austoker J, Rose PW. Long-term survivors of adult cancers and uptake of primary health services: a systematic review. Eur J Cancer. 2008;44:195-204.

22. Wilkins KL, Woodgate RL. Preventing second cancers in cancer survivors. Oncol Nurs Forum. 2008;35:E12-22.

23. Treanor C, Donnelly M. An international review of the patterns and determinants of health service utilisation by adult cancer survivors. BMC Health Serv Res. 2012;12:316.

24. Higgins JPT, Green S Cochrane Handbook for Systematic Reviews of Interventions Version 5.0.2. [Updated September 2009]. The Cochrane Collaboration. Available from: http://www.cochrane-handbook.org/.

25. Hayden JA, Cote P, Bombardier C. Evaluation of the quality of prognosis studies in systematic reviews. Ann Intern Med. 2006;144:427-37.

26. Olivo SA, Macedo LG, Gadotti IC, Fuentes J, Stanton T, Magee DJ. Scales to assess the quality of randomized controlled trials: a systematic review. Phys Ther. 2008;88:156-75.
27. Aparicio-Ting F, Ramirez AG. Breast and cervical cancer knowledge, attitudes, and screening practices of Hispanic women diagnosed with cancer. J Cancer Educ. 2003;18:230-6.

28. Bellizzi KM, Rowland JH, Jeffery DD, McNeel T. Health behaviors of cancer survivors: examining opportunities for cancer control intervention. J Clin Oncol. 2005;23:8884-93.

29. Earle CC, Burstein HJ, Winer EP, Weeks JC. Quality of non-breast cancer health maintenance among elderly breast cancer survivors. J Clin Oncol. 2003;21:1447-51.

30. Grunfeld E, Moineddin R, Gunraj N, Del Giudice ME, Hodgson DC, Kwon JS, et al. Cancer screening practices of cancer survivors: population-based, longitudinal study. Can Fam Physician. 2012;58:980-6.

31. Khan N, Carpenter L, Watson E, Rose P. Cancer screening and preventative care among long-term cancer survivors in the United Kingdom. Br J Cancer. 2010;102:1085-90.

32. Kwon JS, Elit L, Saskin R, Hodgson D, Grunfeld E. Secondary cancer prevention during follow-up for endometrial cancer. Obstet Gynecol. 2009;113:790-5.

33. Mayer DK, Terrin NC, Menon U, Kreps GL, McCance K, Parsons SK, et al. Screening practices in cancer survivors. J Cancer Survivorship. 2007;1:17-26.

34. McBean AM, Yu X, Virnig BA. Screening mammography rate and predictors following treatment for colorectal cancer. J Cancer Survivorship. 2009;3:12-20.

35. McBean AM, Yu X, Virnig BA. The use of preventive health services among elderly uterine cancer survivors. Am J Obstet Gynecol. 2008;198:86.e1-8.

36. Ng AK, Li S, Recklitis C, Diller LR, Neuberg D, Silver B, et al. Health practice in long-term survivors of Hodgkin's lymphoma. Int J Radiat Oncol Biol Phys. 2008;71:468-76.

37. Oeffinger KC, Ford JS, Moskowitz CS, Diller LR, Hudson MM, Chou JF, et al. Breast cancer surveillance practices among women previously treated with chest radiation for a childhood cancer. JAMA. 2009;301:404-14.

38. Snyder CF, Frick KD, Kantsiper ME, Peairs KS, Herbert RJ, Blackford AL, et al. Prevention, screening, and surveillance care for breast cancer survivors compared with controls: changes from 1998 to 2002. J Clin Oncol. 2009;27:1054-61.

39. Snyder CF, Frick KD, Peairs KS, Kantsiper ME, Herbert RJ, Blackford $\mathrm{AL}$, et al. Comparing care for breast cancer survivors to non-cancer controls: a five-year longitudinal study. J Gen Intern Med. 2009;24:469-74.

40. Yeazel MW, Oeffinger KC, Gurney JG, Mertens AC, Hudson MM, Emmons KM, et al. The cancer screening practices of adult survivors of childhood cancer. Cancer. 2003;100:631-40.

41. Hudson SV, Hahn KA, Ohman-Strickland P, Cunningham RS, Miller SM, Crabtree BF. Breast, colorectal and prostate cancer screening for cancer survivors and non-cancer patients in community practices. J Gen Intern Med. 2009;24:487-90.

42. Brouwers M, De Vito C, Carol A, Carroll J, Cotterchio M, Dobbins $\mathrm{M}$, et al. Interventions to increase the uptake of cancer screening. Available from: http://www.cancercare.on.ca/common/pages/ UserFile.aspx?fileId=43168. Accessed 24 June 2011. 